\title{
An Investigation of the Effect of COVID-19 on OCD in Youth in the Context of Emotional Reactivity, Experiential Avoidance, Depression and Anxiety
}

\author{
İsmail Seçer ${ }^{1}$ (D) S Sümeyye Ulaş ${ }^{2}$
}

Published online: 13 June 2020

C) Springer Science+Business Media, LLC, part of Springer Nature 2020

\begin{abstract}
In addition to the serious physical and medical effects on individuals, the COVID-19 pandemic is likely to have short- and long-term psycho-social consequences, especially for young people. Nowadays, with psychological problems becoming more widely recognized in adolescents, it is possible that the fear and anxiety caused by the pandemic will trigger various anxiety disorders, OCD and similar negative outcomes. Considering that psychological qualities such as emotional reactivity and experiential avoidance observed in adolescents may increase the risk of such psycho-social disorders, in this study the relationship between fear of COVID-19 and OCD was investigated in a Turkish sample of 598 adolescents, and the mediating role of emotional reactivity, experiential avoidance and depression-anxiety in this relationship was examined. The data collection was performed online rather than in person because of the COVID-19 threat. A structural equation model was used to determine the direct and indirect predictive effects between variables in data analysis. The results of the study show that the effect of COVID-19 fear on OCD is mediated by emotional reactivity, experiential avoidance and depressionanxiety.
\end{abstract}

Keywords COVID-19 fear · Emotional reactivity $\cdot$ Experiential avoidance $\cdot$ Depression $\cdot$ OCD

Electronic supplementary material The online version of this article (https://doi.org/10.1007/s11469-020$00322-z)$ contains supplementary material, which is available to authorized users.

İsmail Seçer

ismailsecer84@gmail.com

1 Counseling and Guidance, Faculty of Education, Ataturk University, Erzurum, Turkey

2 Counseling and Guidance, School of Health, Gümüşhane University, Gümüşhane, Turkey 


\section{Introduction}

Coronavirus disease 2019 (COVID-19) began as an epidemic in China in December of 2019 and rapidly spread throughout the world, affecting countries and individuals of all ages in many ways (WHO 2020). Due to the severity of the pandemic and the speed of its spread, although the focus is currently primarily on its physical and medical effects, both the restrictive factors such as quarantine and the exaggerated importance given to social distancing rules, in addition to the fear and stress caused by the attitudes exhibited both in the media and by parents, are expected to have psycho-social consequences among adolescents as a secondary effect of the outbreak. The effects of pandemics extend beyond the biological and medical manifestations, and their wide-ranging psycho-social effects can be felt by all of society (Banerjee 2020), with possible serious psychological and psychiatric outcomes (Ornell et al. 2020).

After the COVID-19 outbreak was declared a pandemic by the World Health Organization (WHO 2020), the information about the infection of the virus, incubation period, geographical extent and rising mortality rates, and in particular the images reflected in visual and social media (Wang et al. 2019), is thought to have created serious insecurity in individuals, and the restrictive measures urgently applied in various countries triggered fear due to the pandemic. The information revealed by various sources regarding the contagiousness of the virus may have also increased individuals' fear of becoming infected themselves and infecting their loved ones.

Fear is a defense mechanism an individual shows against dangerous situations and includes the basic reactions necessary to survive these threatening situations. However, fear that is not proportional to the current conditions may lead to various psychological disorders such as anxiety, depression and obsessive-compulsive disorder (OCD) (Garcia 2017; Shin and Liberzon 2010). Even in healthy individuals, there may be a risk of intensified symptoms such as stress, and thus increased risk of psychological disorders. However, research on past pandemics has shown that even after a pandemic, negative psycho-social effects can continue for long periods (Ornell et al. 2020; Shigemura et al. 2020). In this context, studies have shown that the psycho-social effects created by the Ebola epidemic affected the rate of deaths that were an indirect result of the epidemic (Shultz et al. 2016). Research results reporting that negative and traumatic childhood experiences have a strong relationship with adulthood OCD symptoms can also be evaluated in this context (Briggs and Price 2009). Therefore, the fear created by the pandemic carries the risk of secondary consequences in the long term.

Although there is no definitive epidemiological data regarding the psychological effects of COVID-19 on individuals and its effect on public health today, the results of a limited number of studies are quite remarkable. For example, studies have reported that one-third of interviewees in China and Japan developed severe anxiety, and about half developed moderate anxiety (Wang et al. 2020; Shigemura et al. 2020). Similarly, studies have found that fear of contracting COVID19 leads to intense emotional and behavioral consequences such as boredom, loneliness, anxiety, sleep problems and anger (Brooks et al. 2020). It has been reported that depression, anxiety disorders, post-traumatic stress disorder (PTSD), paranoid and psychotic disorders, and even suicide may be among the emotional and behavioral consequences of fear caused by COVID-19 (Wang et al. 2020). Studies have shown that these types of reactions, which can develop based on the state of fear, may be more common in individuals who previously experienced psychological disorders and encountered quarantine or prolonged curfews (Brooks et al. 2020). In addition, intense fear and stress may arise in individuals experiencing symptoms of other health problems (flu, cold, etc.) that are similar to COVID-19 symptoms, and this condition may worsen psychological symptoms (Wang et al. 2020; Park and Park 2020). 
The data from the literature show that, due to fear of COVID-19, individuals may develop emotional and behavioral symptoms with psycho-social outcomes. Given the nature of the pandemic and the impact of social reactions, the risk of developing OCD subtypes, such as washing, hoarding and control, is considered highly probable.

The promotion of hand washing as an effective method against infection (WHO 2020) has increased the emphasis on cleanliness practices using soap and disinfectants. The use of masks and gloves has been made widespread and even compulsory. In particular, the guidelines from infectious disease specialists and authorities stating that the simplest way to protect oneself from the virus is adherence to cleanliness and social distancing can have more serious implications for those who already have intense concerns about cleanliness and hygiene or who have been diagnosed with OCD (Banerjee 2020), and this aspect is significantly neglected due to the severity of the pandemic and the urgency of the measures. With a 2-3\% prevalence in the general population and an image mostly accompanied by anxiety disorders and depression even in the pre-pandemic period, there is a possibility of aggravation of various internal and external stressors (Benerjee 2020), even though OCD responds well to psychological and pharmacological treatments. The worsening of these symptoms may occur over time due to the influence of common factors during the pandemic. Depending on these effects, in addition to the frequent reminders of the importance of cleanliness and hygiene by various sources, it is thought that hoarding, which is another symptom of OCD, can become an important problem. That is, the anxiety and fear experienced lead to a serious risk of the hoarding of masks, soaps, disinfectants, antiviral drugs, allergy medications and protective clothing, and cause panic in grocery shopping (Banerjee 2020; Cordeiro et al. 2015) because of the unavailability of items needed for quarantine measures; examples in the media of such scenarios in the face of imminent quarantines in various countries confirm this risk. Therefore, it is extremely important for experts to consider the development of hoarding as a significant consequence of COVID-19. The prevalence of hoarding, which occurred at a rate of $2-5 \%$ before the pandemic period, may increase significantly due to the virus and related quarantines imposed. Although there is not yet enough data in this direction, it has been reported in the news that the number of individuals seeking hospital care because of OCD symptoms has increased in many countries (www.time.com).

It is thought that some psychological qualities that individuals possess may increase the risk of fear and anxiety created by the pandemic in terms of OCD-like disorders. Among these characteristics, emotional reactivity can be exhibited, which is defined as the intensity of emotions experienced by the individual in various situations and the reactions related to this intensity (Nock et al. 2008). Since the fear of COVID-19 cannot be studied in many ways as it is quite a new issue, it can be difficult to predict its effect on emotional reactivity. However, there are studies showing that daily events and difficult living conditions and various traumas put pressure on emotional reactivity (Glaser et al. 2006; Wichers et al. 2009). As a result of the COVID-19 situation, individuals can be expected to show negative emotions due to events they have witnessed and the fear developed as a result of the information obtained. There are studies showing that the negative emotions in question are related to major depression (Bylsma et al. 2007), which is one of the most severe psychopathologies that an individual can experience throughout life, as well as anxiety disorders (McLaughlin et al. 2010, Seçer 2015) and OCD symptoms (Ekman 1992; McCubbin and Sampson 2006). Therefore, it can be expected that negative emotional reactivity due to the COVID-19 pandemic may pose a risk for depression, anxiety and OCD in adolescents. As such, an understanding of the role of emotional reactivity in the relationship between fear of COVID-19 and OCD symptoms may shed light on prevention and intervention approaches. 
Another type of response likely to occur due to the fear of COVID-19 is experiential avoidance. Experiential avoidance is defined as reluctance to experience emotions, thoughts, memories and physical feelings that are perceived as negative, and reactions to reduce the frequency or effect of these experiences (Hayes et al. 1996). It is also expressed as an attitude that the individual adopts in a strict, constant and continuous manner in the face of negativity, and is associated with various psychological problems in this respect (Ottenbreit and Dobson 2004). This concept, which includes both different experiences avoided and different strategies used for avoidance, also covers the cognitive, emotional and behavioral dimensions of avoidance. Experiential avoidance strategies such as distraction, inhibition, denial or suppression used to control or eliminate negative experiences lead to continuing experiences that people have avoided in the long run and increasing problems related to them (Briggs and Price 2009; Hayes et al. 2012). It is thought that the possible avoidance responses due to COVID-19 fear may play an important role in the emergence and persistence of many psychological problems in this process. Clinical and non-clinical studies have shown that increased experiential avoidance aggravates conditions such as anxiety disorders (Santanello and Gardner 2007), depression (Cribb et al. 2006), social anxiety (Mahaffey et al. 2013), eating disorders (Rawal et al. 2010), post-traumatic stress (Orcutt et al. 2005), low subjective well-being (Machell et al. 2015) and OCD. In this respect, the avoidance responses that adolescents will develop in the process of COVID-19 will also have a negative effect on OCD and lead to chronic symptoms or development of new symptoms due to fear of COVID-19.

\section{The Current Study}

The aim of this study is to examine the mediating role of emotional reactivity, depressionanxiety and experiential avoidance in the relationship between the fear of COVID-19 and OCD symptoms in adolescents. Determining the network of relationships between these variables will contribute to widening our perspective and will help to shape the intervention and action plans aimed at reducing the symptoms of OCD that develop due to the fear caused by the pandemic in young people. In addition, revealing the psychological effects that are among the secondary outcomes of the traumatic-like COVID-19 pandemic, which adolescents face for the first time, will provide an important data source for psychiatrists and psychologists.

In this context, answers were sought to the following questions.

1. Is COVID-19 fear a significant predictor of OCD symptoms?

2. Are emotional reactivity, depression-anxiety and experiential avoidance significant predictors of OCD symptoms in adolescents?

3. Do emotional reactivity, depression-anxiety and experiential avoidance have a mediating role in the relationship between COVID-19 fear and OCD symptoms?

\section{Materials and Methods}

\section{Participants}

The study consists of 598 adolescents, whose ages range between 14 and 18 years (mean = $16.40, \mathrm{SD}=2.14$ ). A total of $61.10 \%$ of the participants are female and $38.9 \%$ are male. During the study, a two-stage process was followed in determining the participants. The data 
collection process was carried out online, since the schools were suspended and a curfew was applied to individuals under 20 years of age because of the pandemic. In this context, data were collected from a total of 598 high school students who could be reached using a convenience sampling method. The data collection process was applied to the provincial education directorate in order to reach all seven regions of Turkey. The students included in the sample were determined by school principals and school psychological counselors with the support of the R\&D units within these directorates, and the data were collected by sending an online data collection link to the students' smartphones or via mail.

\section{Measures}

The Obsessive Compulsive Inventory-Child Version is a Likert-type measurement tool based on a self-report developed to determine obsessive-compulsive symptoms in children and adolescents (Foa et al. 2010). In the scale development process, an item pool consisting of 42 items was created by the researchers, and after reliability and validity studies, a scale consisting of 21 items and six sub-dimensions explaining $49.95 \%$ of the total variance was obtained. The scale consists of sub-dimensions such as doubting-checking, obsessing, hoarding, washing, ordering and neutralizing. The scale was adapted for the Turkish culture in a normal population in the 13-18-year age group (Seçer 2014a, b). In the adaptation process, confirmatory factor analysis (CFA) was used to determine the construct validity of the scale, and it was determined that the 21-item and six sub-dimensional structures in the original version of the scale were preserved in Turkish culture, and their fit indices were good $\left(\chi^{2} /\right.$ SD = 2.94; REMSEA: .067 RMR: .011, SRMR: .065, CFI: .96). The reliability values of the scale were determined as $.73, .76, .81, .78, .79$ and .846 for the sub-dimensions, respectively. In the adaptation process, as a result of the analysis on the factor structure and reliability of the scale, it was evaluated that its psychometric properties were sufficient. Within the scope of this research, the factor structure of the scale was reviewed based on the data obtained from the study group, and the model consistency index $\left(\chi^{2} / \mathrm{SD}=1.95\right.$; REMSEA: .063 , RMR: .041 , SRMR: .060, CFI: .97) and the internal consistency coefficient Cronbach alpha $=.86$ were determined to be sufficient. The response options for practitioners are never, rarely, sometimes, often and always. High scores from the scale and the sub-dimensions indicate a high level of obsessive and compulsive symptoms.

Emotional Reactivity Scale This is a Likert-type measurement tool based on a self-report developed for children and adolescents (Nock et al. 2008). The scale evaluates the emotional response patterns of individuals in relation to interpersonal relationships and various situations. The scale consists of 21 items, and three sub-dimensions: responsiveness, psychological resilience and emotional sensitivity. In the process of adaptation to Turkish culture, the model fit of the scale consisting of 17 items and three sub-dimensions $\left(\chi^{2} / \mathrm{SD}=1.98\right.$; REMSEA: .068 , RMR: .012, SRMR: .066, CFI: .93), and sub-dimension consistency values of .82, .76 and .71, respectively, were determined to be sufficient psychometrically (Seçer et al. 2013). Within the scope of this research, the factor structure of the scale was reviewed over the data obtained from the study group, and the model fit indices $\left(\chi^{2} / \mathrm{SD}=2.16\right.$; REMSEA: .042 , RMR: .030, SRMR: .042, CFI: .98) and the internal consistency coefficient Cronbach alpha = .81 were determined to be sufficient. Response options for practitioners are never, rarely, often and always. The high scores from the scale and sub-dimensions are evaluated as high emotional reactivity. 
Depression and Anxiety Scale for Children This scale is a Likert-type measurement tool based on a self-report developed to measure depression and anxiety symptoms in children and adolescents (Ebesutani et al. 2012). The scale consists of 25 items in total and two subdimensions. In the original version of the scale, the anxiety dimension was tested as one dimension and five different dimensions. In the process of adaptation to Turkish culture, the suitability of the factor structure of the scale was examined with CFA, and it was determined that the structure consisting of two sub-dimensions, depression and anxiety, and 25 items fit better than the six-factor structure $\left(\chi^{2} / \mathrm{SD}=1.49\right.$; REMSEA: .071, RMR: .065 SRMR: .070 , CFI: .98). Internal consistency scores of the scale were found to be .87 for the depression subscale and .83 for the anxiety subscale (Ay et al. 2017). Within the scope of this research, the factor structure of the scale was reviewed over the data obtained from the study group, and the model fit indices $\left(\chi^{2} / \mathrm{SD}=1.13\right.$; REMSEA: .032, RMR: .021, SRMR: .029, CFI: .97) and the internal consistency coefficient Cronbach alpha $=.87$ were determined to be sufficient. Response options for practitioners are never, rarely, often and always. The high scores of the scale and sub-dimensions are evaluated as high depression and anxiety symptoms.

The Fear of COVID-19 Scale This is a self-reported scale consisting of seven items and a single dimension developed to measure anxiety and depressive symptoms that develop due to the outbreak of COVID-19 in individuals (Ahorsu et al. 2020). The scale is a four-point Likerttype measurement tool for individuals in the age group 18 years and older. Although the scale was adapted to Turkish culture for adults (Satıc1 et al. 2020), it was also adapted to Turkish culture for the 14-19-year age group within the scope of this research, and its psychometric properties were examined. CFA was applied to examine the model fit of the scale, and it was determined that seven items and a one-dimensional structure in the original version were preserved $\left(\chi^{2} / \mathrm{SD}=2.10\right.$, REMSEA: .041, RMR: .037, SRMR: .040, CFI: .99). The internal consistency value of the scale was determined as .91. The scores that can be obtained from the scale vary between 0 and 28, and the high scores indicate a high level of COVID-19 fear and related responsiveness.

Experiential Avoidance Questionnaire The questionnaire is a self-reported seven-point Likert-type measurement tool adapted to Turkish culture (Sahdra et al. 2016) and developed to determine the avoidance responses of individuals against various experiences (Ekși et al. 2018). The sub-dimensions included in the scale are behavioral avoidance, distress aversion, procrastination, distraction/suppression, repression/denial and distress endurance. There are five items in each sub-dimension, and the scale consists of 30 items in total. In the scale, only the scores of the sub-dimensions are calculated instead of the total score, and high scores indicate problematic avoidance in the relevant sub-dimension. Within the scope of this research, the factor structure of the scale was reviewed based on the data obtained from the study group, and the model fit indices $\left(\chi^{2} / \mathrm{SD}=2.41\right.$; REMSEA: .071 , RMR: .073 , SRMR: .070 , CFI: .98) and internal consistency coefficient Cronbach alpha $=.85$ were determined to be sufficient.

\section{Procedure and Data Analyses}

Before the study was begun, permission to conduct the research was obtained from the Ataturk University Health Sciences Ethics Committee, and the necessary permission was then 
provided by the respective local administrators. In adherence to legal procedures, it was determined that only online methods for data collection were advisable, since the COVID19 outbreak is very intense and curfews have been widely applied. Accordingly, the online data collection link (available at https://forms.gle/ZRAyWFHgy9BbJgwx9) prepared via Google Forms was delivered to target students via mail and WhatsApp-like applications. In this context, the students who volunteered to participate in the study and who had the consent of their parents were determined through the provincial directorates of national education, school principals and school psychological counselors, and an online survey link was sent to these students. A link to an informed consent form for students and their volunteer participation was added to the online questionnaire form. In addition, the students were informed that they could withdraw from the survey at any time and that the data would be kept confidential. The online data collection process was completed within 15 days. Data collection and compilation were carried out by two researchers who specialize in psychology and counseling. The data collected online in the computer environment were analyzed. There were no missing data, since the scales were completed online and each question required an answer. Therefore, extreme value, normality and homogeneity tests were applied directly. The data for 11 individuals were found to violate the parametric conditions, and they were removed from the data set. At the last stage, the normality values were examined using LISREL 9 software, and it was found that the data set showed a normal and homogeneous distribution without applying a transformation process.

After the parametric conditions were provided, confirmatory measurement and structural equation models were individually constructed and tested to find answers to the research questions. The confirmatory measurement model was designed and tested to examine the compatibility levels of variables defined as structure at the first step in the data analysis. In the measurement model, five different implicit variables (COVID-19, emotional reactivity, experiential avoidance, depression and anxiety, obsessive-compulsive disorder) and 16 observed variables represented by these implicit variables were used in the confirmatory analysis. Verification of measurement models is an important prerequisite for testing structural equation models (Seçer 2015). In this context, the findings related to the measurement model tested $\left(\chi^{2} /\right.$ SD = 1.69; REMSEA: .069, RMR: .064, SRMR: .066, NFI: .93, CFI: .95, GFI: .92) show that the constructed model was verified and that all implicit variables fit well with the indicator variables and other implicit variables (Tabachnick and Fidell 2013).

After verification of the measurement model, three different models were designed and tested in the second stage to seek answers to the research questions. The models tested in the structural equation model were tested in Model 1 for the direct procedure of the obsessivecompulsive disorder of COVID-19 fear. In Model 2, emotional reactivity, experiential avoidance, depression and anxiety were included in the model, and it was examined whether COVID-19 fear could predict obsessive-compulsive disorder both directly and through the included variables. In Model 3, the direct predictive paths between COVID-19 fear and obsessive-compulsive disorder were removed from the model, and their mediation relationships were tested. In structural equation modeling, different fit indices are used for model fit. The fit indices used are CFI, NFI, GFI, AGFI, RMR, SRMR, RMSEA and $\chi^{2}$ In the structural equation model, different criteria are proposed for these fit indices. Schumacker and Lomax (2004) and Tabachnick and Fidell (2013) suggest that in the structural equation model, model fit indices should be $\geq .90$ for acceptable fit and $\geq .95$ for perfect fit for RFI, TLI, CFI, NFI, NNFI and IFI; $\geq .85$ for acceptable fit and $\geq .90$ for perfect fit for GFI and AGFI; and $\leq .08$ for acceptable fit and $\leq .50$ for perfect fit for RMR, REMSEA and SRMR. 


\section{Results}

Three different models were tested for the purposes of the research. First, as model 1, the research hypothesis constructed as "Fear of COVID-19 directly predicts obsessive-compulsive disorder" was tested. In this model, fear of COVID-19 is expected to positively predict obsessive-compulsive disorder in children. The findings are presented in Fig. 1.

Considering the fit indices values $\left(\chi^{2}(92,39)=64 ; \mathrm{CFI}=0.95 ; \mathrm{TLI}=0.94 ; \mathrm{NFI}=0.94\right.$; GFI $=0.92)$ of the model tested in Fig. 1 , it can be said that the implicit variables in Model 1 have a significant relationship with the observed variables they represent $(p<.001)$. Model 1 shows that seven structures that explain COVID-19 predicted the structure that described OCD positively and directly as expected $(\beta=.60, p<.01)$. Considering the findings and correlation coefficients, the fear of COVID-19 shows a strong effect on OCD in adolescents (36\%), and the hypothesis constructed is confirmed. In addition, Model 2 and Model 3 need to be examined in order to better understand the direct relationship processes between these variables.

After verification of the hypothesis constructed as Model 1, the second stage of the mediation relations should be applied. At this stage, variables whose mediating effect is examined are included in the model, and parameters related to the direct and indirect relationships between the predictor and outcome variables are examined. In this context, the variables emotional reactivity, experiential avoidance, depression and anxiety were included in the model tested in Model 1, and this model was labeled Model 2.

Model 2 was structured as "Emotional reactivity, experiential avoidance, depression and anxiety variables mediate the relationship between COVID-19 fear and obsessive-compulsive disorder", and the findings obtained are presented in Fig. 2.

Considering the findings related to Fig. 2, a significant change in the parameters reached in Model 1 was observed after the variables emotional reactivity, experiential avoidance and depression and anxiety were included in the model. The general rule in mediation relations is that there is a significant decrease in the direct predictive coefficients obtained in Model 1 when the mediating variable is included in the model. In this sense, when Fig. 2 is examined, it can be seen that COVID-19 fear is a direct predictive coefficient $(=.19, p<.01,3.6 \%)$ with

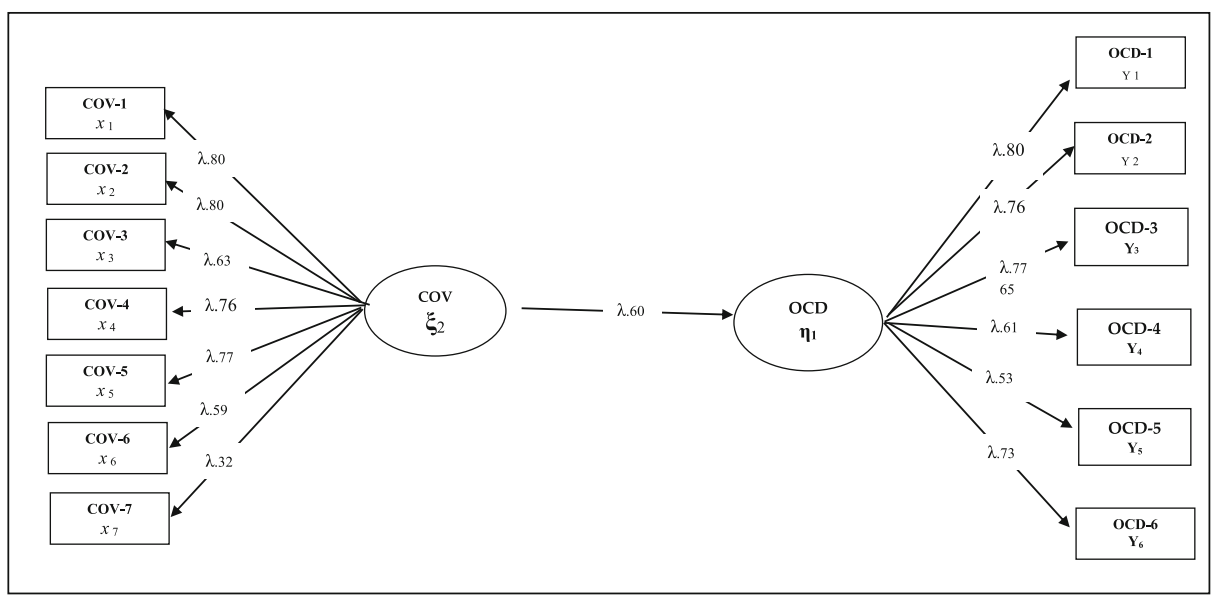

Fig. 1 Standardized structural equation modeling (SEM) results for Model 1 


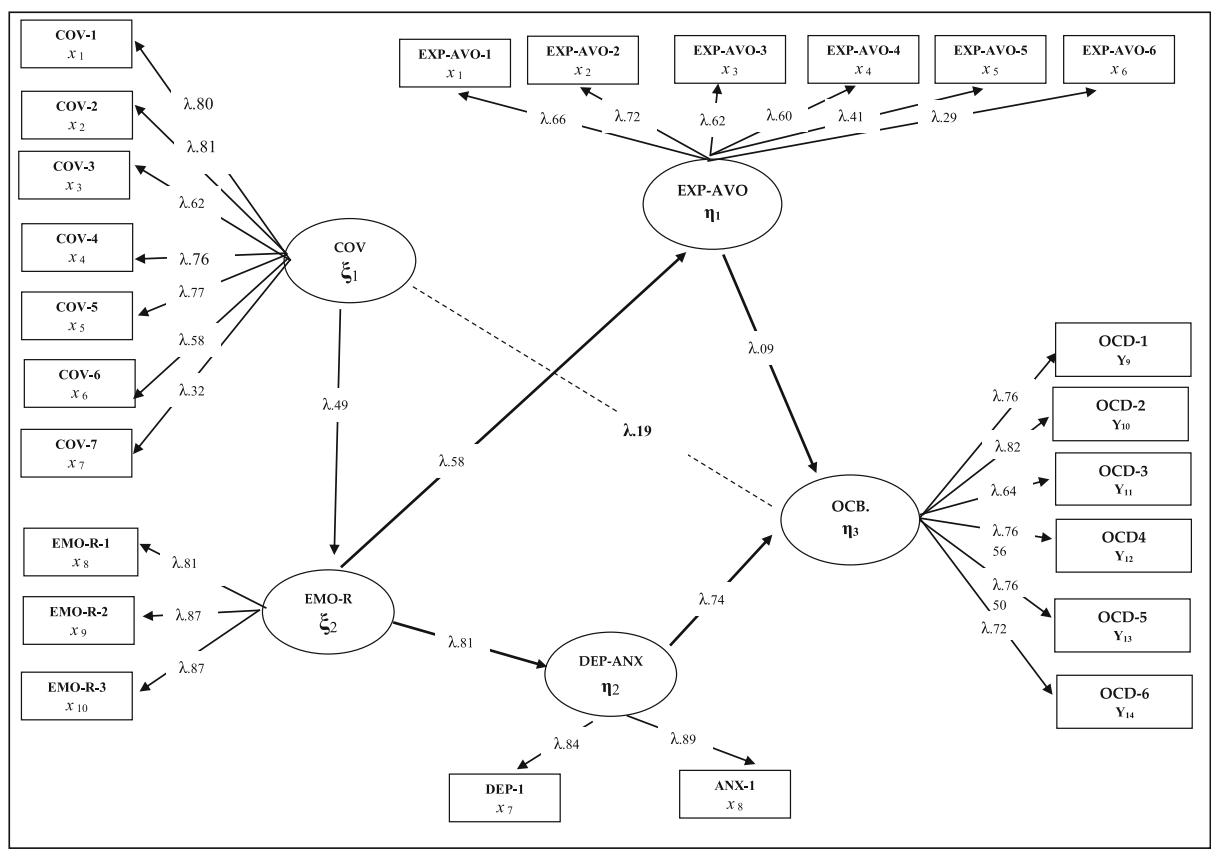

Fig. 2 Standardized structural equation modeling (SEM) results for Model 2

respect to OCD. However, the same predictive coefficients were found as $(\beta=.60, p<.01$, $36 \%$ ) in Model 1. These findings obtained in Model 2 strengthen the idea that the variables included in the model may have an intermediary role, because there is a significant decrease in the direct predictive coefficient between the fear of COVID-19 and OCD. When the predictive coefficients of variables included in the model on OCD are analyzed, experiential avoidance $(\beta=.09, p<.01)$ and depression-anxiety $(\beta=.74, p<.01)$ are found to have positive and significant predictive coefficients. In addition, emotional reactivity, which is another variable in the model, is positively predicted by the fear of COVID-19 $(\beta=.49, p<.01)$, and emotional reactivity is highly correlated with experiential avoidance $(\beta=.58, p<.01)$ and depressionanxiety $(\beta=.81, p<.01)$.

Considering the fit indices for Model 2, the model that was constructed is found to have a good fit $\left(\chi^{2}(382.42)=246 / 1.55\right.$; CFI $=0.95$; TLI $=0.95$; SRMR $=0.06$; RMSEA $\left.=0.06\right)$. Although the model was validated, the significant decrease observed in the predictive coefficients between the fear of COVID-19 and OCD after intermediary variables were included in the model made it necessary to test the full mediation relationship. In this context, the model was reconstructed; the direct path from COVID-19 fear to OCD was removed from the model (Model 3), and the full mediation role of the variables emotional reactivity, experiential avoidance, and depression and anxiety was tested.

Model 3 was structured as "Emotional reactivity, experiential avoidance, and depression and anxiety variables are fully mediated in the relationship between COVID-19 fear and obsessive-compulsive disorder", and the structural model addressing the full mediation relationship is presented in Fig. 3.

Fit indices and parameters related to Model 3, which tests the full mediating role of the variables emotional reactivity, experiential avoidance, and depression and anxiety $\left(\chi^{2}\right.$ 


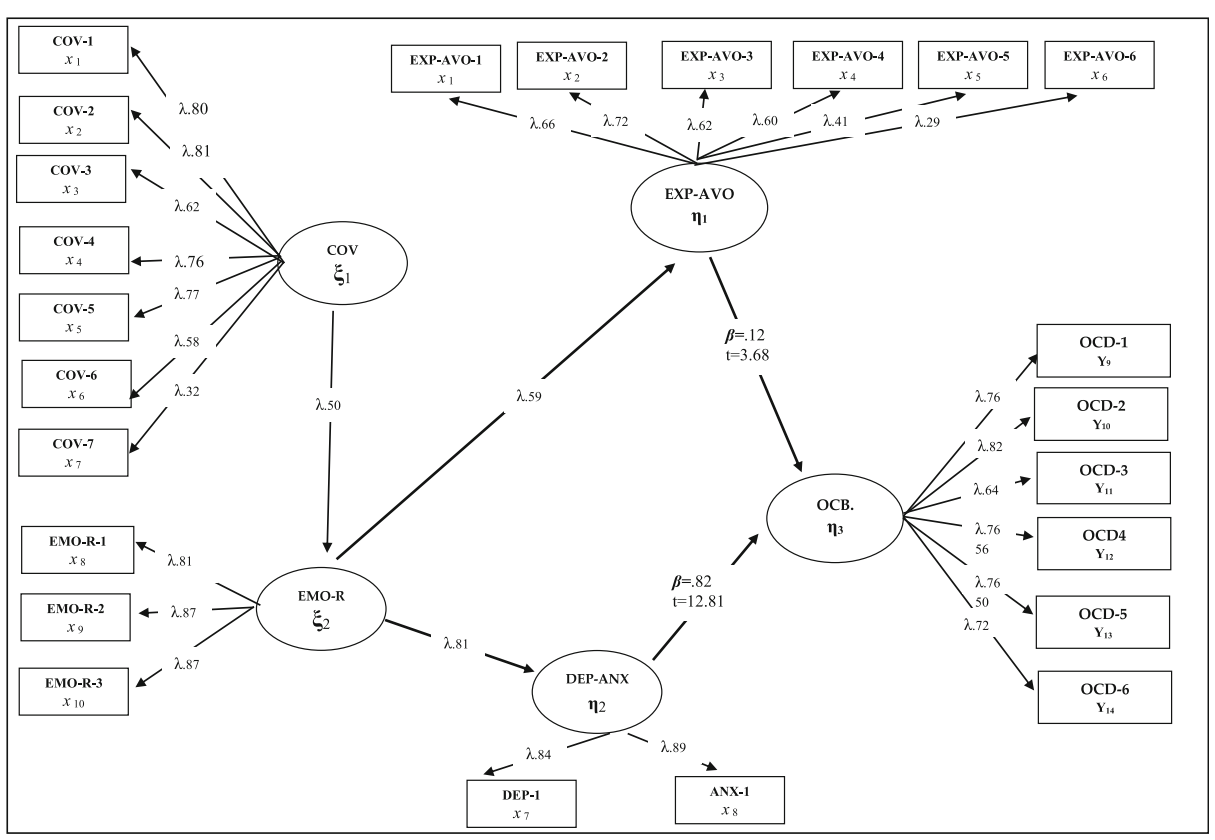

Fig. 3 Standardized structural equation modeling (SEM) results for Model 3

$(247)=487.16 / 1.97 ; \mathrm{CFI}=0.96 ; \mathrm{TLI}=0.96 ; \mathrm{SRMR}=0.062 ; \mathrm{RMSEA}=0.062)$, show that the mediation role of the tested model and the variables emotional reactivity, experiential avoidance, and depression and anxiety are validated. When Fig. 3 is examined, it is seen that the fear of COVID-19 positively predicts emotional reactivity $(\beta=.50, p<.01)$, and emotional reactivity positively predicts experiential avoidance $(\beta=.59, p<.01)$ and depression-anxiety $(\beta=.81, p<.01)$. In addition, experiential avoidance has positive and significant predictive effects on $\operatorname{OCD}(\beta=.12, p<.01)$ and depression-anxiety on $\operatorname{OCD}(\beta=.82, p<.01)$, and in this model, the fear of COVID-19 is a stronger predictor of OCD compared with the findings obtained in MODEL 2 for emotional reactivity, experiential avoidance and depression-anxiety. It can be said that removing the direct pathways (COVID-19> OCD) that have low relation in Model 2 was effective with regard to the change that appeared positively in the predictive coefficients in question.

\section{Discussion}

The Relationship between the Fear of COVID-19 and OCD Symptoms and the Mediating Role of Emotional Reactivity, Depression-Anxiety and Experiential Avoidance

In line with the results of this study, the predictive effect of COVID-19 fear on OCD symptoms in adolescents can be discussed in two ways: the direct effects, and the indirect effects through the variables of emotional reactivity, depression-anxiety and experiential avoidance. 
Research results show that fear of COVID-19 has a positive and significant effect on OCD. Considering possibilities such as the speed of disease spread and the risk of death, it may be reasonable for adolescents to have washing and hoarding obsessions. It is thought that anxiety sensitivity known as the expectancy model of fear can be effective in explaining this relationship (Reis and McNally 1985; Seçer 2015). Anxiety caused by an individual's intense expectation that adverse conditions will arise due to COVID-19 may trigger OCD symptoms, and it may worsen washing and hoarding behaviors in particular. When Model 1, which deals with the effect of COVID-19 fear on OCD symptoms, is examined, it will be seen that there is a very high correlation coefficient. In addition, when Model 2 and Model 3, which are designed considering that some variables may mediate this relationship, are analyzed, an indirect effect of COVID-19 fear on OCD is found, and the variables included in the model have an intermediary relationship.

Although fear of COVID-19 in Model 1 has a high-level relationship with OCD, with the addition of emotional reactivity, depression-anxiety and experiential avoidance in Model 2, the significant decrease in this prediction coefficient indicates that both type II errors are prevented, and there is a mediation relationship. Accordingly, the fear of COVID-19 creates its effect on OCD through other qualifications of the adolescents. This effect appears to be related to emotional reactivity in the first step. High emotional reactivity makes the effect of COVID19 fear on OCD evident. The results of studies (Glaser et al. 2006; McCubbin and Sampson 2006; Wichers et al. 2009) discussing the effect of emotional reactivity on various psychopathologies seem to support this result. Therefore, it is possible that the negative emotional reactivity that can occur as a result of the fear associated with the COVID-19 outbreak may pose a risk of depression, anxiety and OCD in adolescents. Hence, a consideration of the negative emotional reactivity in the examination of OCD symptoms thought to develop due to the fear of COVID-19 can increase the effectiveness of the treatment processes.

The second important result of the study is that the fear of COVID-19 is a significant positive predictor of depression-anxiety symptoms in adolescents, and depression-anxiety also has a positive effect on OCD symptoms. The disproportionate fear of COVID-19 can trigger anxiety and depression symptoms (Ornell et al. 2020; Shigemura et al. 2020; Xiang et al. 2020; Wang et al. 2020), and individuals may engage in intensive washing rituals and hoard a variety of materials that they will need under quarantine as a result of the influence of negative emotional reactivity. In addition, intense secondary emotional and behavioral results such as loneliness, sleep problems, anger and anxiety caused by the fear of COVID-19 can worsen OCD symptoms (Brooks et al. 2020; Park and Park 2020). Thus, it is useful to understand the nature of OCD symptoms that will develop in adolescents as a result of the pandemic and to prioritize depression and anxiety symptoms in diversifying treatment practices.

The third important result obtained from the research is that experiential avoidance mediates the relationship between the fear of COVID-19 and OCD symptoms. Experiential avoidance, which describes the reluctance to experience the processes related to situations considered as negative (Hayes et al. 1996; Briggs and Price 2009), may be considered as a function that transforms the negative mood caused by the fear of COVID-19 into the symptoms of OCD. Experiential avoidance reflects the cognitive, emotional and behavioral response strategies of the individual against a situation (Ottenbreit and Dobson 2004), and negative avoidance approaches associated with COVID-19 can deepen both washing and hoarding obsessions (Briggs and Price 2009; Santanello and Gardner 2007; Mahaffey et al. 2013). In other words, adolescents acting with fear can deepen their obsessions by engaging in dysfunctional avoidance behaviors due to their cognitive errors in making sense of the process 
they are in. Therefore, understanding the nature of OCD symptoms in adolescents and understanding the experiential avoidance in diversifying treatment practices may contribute to ensuring the effectiveness of treatment practices.

\section{Limitations and Future Research}

The findings of this study should be evaluated in the context of its limitations. First, it is significantly limited in terms of revealing a cause-effect relationships, because the research is relational and cross-sectional, and also because the sampling process was based on convenience sampling. Not including a clinical group in the sample should be considered a limitation as well. In addition, the qualities in adolescents were measured based only on self-reports. Therefore, in future research, the choice of a mixed research approach, which includes the opinions of both the adolescents and their parents, through triangulation, may offer a broader perspective. Another limitation is that the study was conducted only with adolescents from a Turkish sample. Conducting a similar study in different cultures and countries will make important contributions to the literature in terms of understanding the symptoms of OCD in adolescents.

\section{Implications}

The results of this study should be of great interest to psychiatrists, psychologists and related researchers. Nowadays, as the negative reflections of the COVID-19 pandemic are becoming increasingly severe, it is thought that highlighting the secondary outcomes of the pandemic and understanding the OCD symptoms that are likely to develop in adolescents will shed light on strategies for studies regarding the planning of treatment processes, and contribute to widening the perspective in this direction. It is also believed that the findings related to the emotional reactivity, depression-anxiety and experiential avoidance processes discussed in the context of mediation roles can be an important data source for experts in this field.

Author Contributions Based on a review of the relevant literature, İS and SU jointly conceived of the research idea. After determining the research subject, both authors took an active role in completing the research procedures. After obtaining the research permissions and ethics committee approvals, the two authors jointly collected and analyzed the data, and created the online data collection processes and delivered them to the target groups. The transfer of the data collected online to the SPSS environment and examination of its suitability for analysis and parametric test conditions were done by İS. Data analysis and reporting processes were done by SU. In the writing of the manuscript, the Introduction and Discussion sections were written chiefly by İS, and SU contributed to this process. The Methods and Findings sections were prepared for publication by SU, with contribution from İS. The Discussion section was written by both authors together. During the publication of the article, the feedback from the editors and the referees was organized by both authors together.

\section{References}

Ahorsu, D.K., Lin, C.Y., Imani, V., Saffari, M., Griffiths, M.D., \& Pakpour, A.H. (2020). The Fear of COVID19 Scale: Development and Initial Validation. International Journal of Mental Health and Addiction:1-9. https://doi.org/10.1007/s11469-020-00270-8.

American Psychiatric Association (APA). (2013). Diagnostic and statistical manual of mental disorders (DSM$5 \circledR)$ American Psychiatric Pub.

Ay, I., Seçer, I., \& Șimşek, M. K. (2017). Adapting depression and anxiety questionnaire for children into Turkish: Reliability and validity studies. International Education Studies, 10(3), 185-193. https://doi. org/10.5539/ies.v10n3p185. 
Banerjee, D. (2020). The other side of COVID-19: Impact on obsessive compulsive disorder (OCD) and hoarding. Psychiatry Research, 288, 112966. https://doi.org/10.1016/j.psychres.2020.112966.

Briggs, E. S., \& Price, I. R. (2009). The relationship between adverse childhood experience and obsessivecompulsive symptoms and beliefs: The role of anxiety, depression, and experiential avoidance. Journal of Anxiety Disorders, 23(8), 1037-1046. https://doi.org/10.1016/j.janxdis.2009.07.004.

Brooks, S. K., Webster, R. K., Smith, L. E., Woodland, L., Wessely, S., Greenberg, N., \& Rubin, G. J. (2020). The psychological impact of quarantine and how to reduce it: Rapid review of the evidence. The Lancet, 395(10227), 912-920. https://doi.org/10.1016/S0140-6736(20)30460-8.

Bylsma, L. M., Morris, B. H., \& Rottenberg, J. (2008). A meta-analysis of emotional reactivity in major depressive disorder. Clinical Psychology Review, 28(4), 676-691. https://doi.org/10.1016/j.cpr.2007.10.001.

Cordeiro, T., Sharma, M., Thennarasu, K., \& Janardhan-Reddy, Y. (2015). Symptom dimensions in obsessivecompulsive disorder and obsessive beliefs. Indian Journal of. Psychological Medicine, 37(4), 403-408. https://doi.org/10.4103/0253-7176.168579.

Cribb, G., Moulds, M. L., \& Carter, S. (2006). Rumination and experiential avoidance in depression. Behaviour Change, 23(3), 165-176. https://doi.org/10.1375/bech.23.3.165.

Ebesutani, C., Reise, S. P., Chorpita, B. F., Ale, C., Regan, J., Young, J., Higa-McMillan, C., \& Weisz, J. R. (2012). The revised child anxiety and depression scale-short version: Scale reduction via exploratory bifactor modeling of the broad anxiety factor. Psychological Assessment, 24(4), 833-845. https://doi.org/10.1037 /a0027283.

Ekman, P. (1992). An argument for basic emotions. Cognition and Emotion, 6, 169-200.

Ekși, H., Kaya, Ç, \& Kuşcu, B. (2018). Multıdımensıonal experıentıal avoıdance questıonnaıre-30: Adaptatıon and psychometric properties of the Turkısh versıon. Annual Congress, 483-487. Available on: https://www. academia.edu/37852402/Çok_Boyutlu_Yaşantısal_Kaçınma_Ölçeği-30_un_Türkçeye_uyarlanması_ve_ psikometrik_Özellikleri_Multidimensional_Experiential_Avoidance_Questionnaire-30_Adaptation_and_Psychometric_Properties_of the_Turkish_Version_.

Foa, E., Coles, M., Huppert, J., Pasupuleti, R., Franklin, M., \& March, J. (2010). Development and validation of a child version of the obsessive compulsive inventory. Behavior Therapy, 41(1), 121-132. https:/doi. org/10.1016/j.beth.2009.02.001.

Garcia, R. (2017). Neurobiology of fear and specific phobias. Learning \& Memory, 24(9), 462-471. https://doi. org/10.1101/lm.044115.116.

Glaser, J. P., van Os, J., Portegijs, P. J., \& Myin-Germeys, I. (2006). Childhood trauma and emotional reactivity to daily life stress in adult frequent attenders of general practitioners. Journal of Psychosomatic Research, 61(2), 229-236. https://doi.org/10.1016/j.jpsychores.2006.04.014.

Hayes, S. C., Strosahl, K. D., \& Wilson, K. G. (2012). Acceptance and commitment therapy: The process and practice of mindful change. New York: Guilford Press.

Hayes, S.C., Wilson, K.W., Gifford, E.V., Follette, V.M., \& Strosahl, K. (1996). Experiential avoidance and behavioral disorders: A functional dimensional approach to diagnosis and treatment. Journal of Consulting and Clinical Psychology, 64(6), 1152-1168. https://doi.org/10.1037/0022-006X.64.6.1152 https://time. com/5808278/coronavirus-anxiety (Accessed on 21th April 2020).

Machell, K. A., Goodman, F. R., \& Kashdan, T. B. (2015). Experiential avoidance and well-being: A daily diary analysis. Cognition \& Emotion, 29(2), 351-359. https://doi.org/10.1080/02699931.2014.911143.

Mahaffey, B. L., Wheaton, M. G., Fabricant, L. E., Berman, N. C., \& Abramowitz, J. S. (2013). The contribution of experiential avoidance and social cognitions in the prediction of social anxiety. Behavioural and Cognitive Psychotherapy, 41(1), 52-65. https://doi.org/10.1017/S1352465812000367.

McCubbin, R. A., \& Sampson, M. J. (2006). The relationship between obsessive-compulsive symptoms and appraisals of emotional states. Journal of Anxiety Disorders, 20(1), 42-57. https://doi.org/10.1016/j. janxdis.2004.11.008.

McLaughlin, K. A., Kubzansky, L. D., Dunn, E. C., Waldinger, R., Vaillant, G., \& Koenen, K. C. (2010). Childhood social environment, emotional reactivity to stress, and mood and anxiety disorders across the life course. Depression and Anxiety, 27(12), 1087-1094. https://doi.org/10.1002/da.20762.

Nock, M. K., Wedig, M. M., Holmberg, E. B., \& Hooley, J. M. (2008). The emotion reactivity scale: Development, evaluation, and relation to self-injurious thoughts and behaviors. Behavior Therapy, 39(2), $107-116$.

Orcutt, H. K., Pickett, S., \& Pope, E. (2005). Experiential avoidance and forgiveness as mediators in the relation between traumatic life events and PTSD symptoms. Journal of Social and Clinical Psychology, 24(7), 1003-1029. https://doi.org/10.1521/jscp.2005.24.7.1003.

Ornell, F., Schuch, J. B., Sordi, A. O., \& Kessler, F. H. P. (2020). "Pandemic fear" and COVID-19: Mental health burden and strategies. Brazilian Journal of Psychiatry, 00, 000-000. https://doi.org/10.1590/15164446-2020-0008. 
Ottenbreit, N. D., \& Dobson, K. S. (2004). Avoidance and depression: The construction of the cognitivebehavioral avoidance scale. Behavior Research and Therapy, 42(3), 293-313. https://doi.org/10.1016 /S0005-7967(03)00140-2.

Park, S. C., \& Park, Y. C. (2020). Mental health care measures in response to the 2019 novel coronavirus outbreak in Korea. Psychiatry Investigation, 17(2), 85-86. https://doi.org/10.30773/pi.2020.0058.

Rawal, A., Park, R. J., \& Williams, J. M. G. (2010). Rumination, experiential avoidance, and dysfunctional thinking in eating disorders. Behaviour Research and Therapy, 48(9), 851-859. https://doi.org/10.1016/j. brat.2010.05.009.

Reis, S., \& McNally, R. J. (1985). Expectancy model of fear. In S. Reiss \& R. R. Bootzin (Eds.), Theoretical issues in behavior therapy (pp. 107-121). San Diego: Academic Press.

Sahdra, B.K., Ciarrochi, J., Parker, P., \& Scrucca, L. (2016). Using genetic algorithms in a large nationally representative American sample to abbreviate the multidimensional experiential avoidance questionnaire. Frontiers in Psychology, 7, 189. doi.org/https://doi.org/10.3389/fpsyg.2016.00189.

Santanello, A. W., \& Gardner, F. L. (2007). The role of experiential avoidance in the relationship between maladaptive perfectionism and worry. Cognitive Therapy and Research, 30(3), 319-332. https://doi. org/10.1007/s10608-006-9000-6.

Satıcı, B., Gocet-Tekin, E., Deniz, M. E., \& Satıcı, S. A. (2020). Adaptation of the fear of Covid-19 scale: Its association with psychological distress and life satisfaction in Turkey. International Journal of Mental Health and Addiction. https://doi.org/10.1007/s11469-020-00294-0.

Schumacker, R.E., \& Lomax, R.G. (2004). A beginner's guide to structural equation modeling. 2nd Edn. Psychology Press.

Seçer, İ. (2014a). Adapting the child version of obsessive-compulsive inventory into Turkish: The study of reliability and validity. Education and Science, 39(176), 355-367. do1: https://doi.org/10.15390 /EB.2014.3516.

Seçer, İ. (2014b). Analysis of the relations between obsessive compulsive symptoms and anxiety sensitivity in adolescents with structural equation modeling. Education and Science, 39(176), 369-382. https://doi. org/10.15390/EB.2014.3517.

Seçer, I. (2015). Practical data analysis with SPSS and LISREL. Ankara: Anı Press

Seçer, İ., Halmatov, S., \& Gençdoğan, B. (2013). Emotional reactivity scale adaptation to Turkish: Reliability and validity study. Sakarya University Journal of Education, 3(1), 77-89.

Shigemura, J., Ursano, R. J., Morganstein, J. C., Kurosawa, M., \& Benedek, D. M. (2020). Public responses to the novel 2019 coronavirus (2019-nCoV) in Japan: Mental health consequences and target populations. Psychiatry and Clinical Neurosciences, 74(4), 281-282. https://doi.org/10.1111/pcn.12988.

Shin, L. M., \& Liberzon, I. (2010). The neurocircuitry of fear, stress, and anxiety disorders. Neuropsychopharmacology, 35(1), 169-191. https://doi.org/10.1038/npp.2009.83.

Shultz, J. M., Cooper, J. L., Baingana, F., Oquendo, M. A., Espinel, Z., Althouse, B. M., et al. (2016). The role of fear-related behaviors in the 2013-2016 West Africa Ebola virus disease outbreak. Current Psychiatry Reports, 18(11), 104. https://doi.org/10.1007/s11920-016-0741-y.

Tabachnick, B., \& Fidell, L. (2013). Using multivariate statistics (6th ed.). Boston: Pearson.

Wang, C., Pan, R., Wan, X., Tan, Y., Xu, L., Ho, C. S., \& Ho, R. C. (2020). Immediate psychological responses and associated factors during the initial stage of the 2019 coronavirus disease (COVID-19) epidemic among the general population in China. International Journal of Environmental Research and Public Health, 17(5), 1729. https://doi.org/10.3390/ijerph17051729.

Wang, Y., McKee, M., Torbica, A., \& Stuckler, D. (2019). Systematic literature review on the spread of healthrelated misinformation on social media. Social Science \& Medicine, 240, 112552. https://doi.org/10.1016/j. socscimed.2019.112552.

Wichers, M., Schrijvers, D., Geschwind, N., Jacobs, N., Myin-Germeys, I., Thiery, E., ... \& Van Os, J. (2009). Mechanisms of gene-environment interactions in depression: Evidence that genes potentiate multiple sources of adversity. Psychological Medicine, 39(7), 1077-1086. do1: https://doi.org/10.1017 /S0033291708004388.

World Health Organization (WHO). (2020). Coronavirus disease (COVID-2019): Situation report-54. Available on: https:/www.who.int/docs/default-source/coronaviruse/situation-reports/20200314-sitrep-54-covid-19. pdf?sfvrsn=dcd46351_2.2

Xiang, Y. T., Yang, Y., Li, W., Zhang, L., Zhang, Q., Cheung, T., \& Ng, C. H. (2020). Timely mental health care for the 2019 novel coronavirus outbreak is urgently needed. The Lancet Psychiatry, 7(3), 228-229. https://doi.org/10.1016/S2215-0366(20)30046-8.

Publisher's Note Springer Nature remains neutral with regard to jurisdictional claims in published maps and institutional affiliations. 